\title{
The effect of crude ethanol extract and fractions of Hyptidendron canum (Pohl ex Benth.) Harley on the hepatopancreas of Oreochromis niloticus L
}

\author{
TATIANA S FIUZA ${ }^{1 *}$, PAULO C SILVA $^{2}$, JOSÉ R PAULA $^{3}$, LEONICE M F $^{2}$ \\ TRESVENZOL ${ }^{3}$ and SIMONE M T SABÓIA-MORAIS ${ }^{1}$ \\ ${ }^{1}$ Laboratory of Cellular Behavior - ICB IV Institute of Biological Science. \\ ${ }^{2}$ Department of Animal Production, School of Medicine Veterinary. \\ ${ }^{3}$ Faculty of Pharmacy, Federal University of Goiás, Goiânia, Goiás, Brazil.
}

\begin{abstract}
Hyptidendron canum (Pohl ex Benth.) Harley is a native tree of the Brazilian Savannah. The fish Oreochromis niloticus $\mathrm{L}$. was used as an experimental model to determine the bioactivity of the crude ethanol extract as well as ethyl acetate, hexanic and chloroform fractions obtained from its leaves. The plant ethanol extract and fractions were administered to the fish orally with their feed. Twenty four hours later, the fish were sacrificed and their livers dissected, fixed in neutral formalin, embedded in paraffin and sectioned. Histological analyses were performed using Masson's trichrome and Haematoxylin-Eosin. Histochemical studies were performed using Feulgen, PAS (Periodic Acid Schiff) and PAS + salivary amylase and Sudan IV stain. The qualitative analysis of the material showed that both the crude ethanol extract and the fractions from $H$. canum induced vasoactive activity, causing vasodilation and vascular congestion, and the hexanic fraction also caused an apparent proliferation of capillaries. Hepatopancreas toxicity was evident through inflammatory processes. Pancreatic (chloroform fraction) and hepatic alterations, hemorrhagic spots and necroses were observed in fish treated with-ethanol extract and fractions. This study is the first description of the biologic action of the crude ethanol extract and the hexane, ethyl acetate and chloroform fractions in fish.
\end{abstract}

Key terms: fish; Nile tilapia; Savannah biome; vasodilation

\section{INTRODUCTION}

The Savannah biome originally encompassed approximately two million square kilometers of Brazilian territory and is the second largest Brazilian biome, comprising approximately $23 \%$ of the vegetation of the country (Ratter et al., 1997). Mitermeier et al. (1999) estimated that $67 \%$ of the Savannah areas could be considered "highly modified" while only $20 \%$ remain undisturbed. Even areas that still retain their original landscapes are affected by water and agro-toxic pollution, erosion, invasive plants and animals, vegetal extraction and predators due to unrestrained industrialization and the lack of conservation awareness (Silva et al.,
2002). If the natural resources found in the savannah become extinct, the therapeutic possibilities offered by their medicinal plants will not be available to future generations (Guarin Neto and Morais, 2003).

Medicinal plants are sometimes the only therapeutic resource for many communities and ethnic groups. The use of plants to treat and cure illnesses is as old as the human species and even today, both in the rural areas of Brazil and in the large cities, medicinal plants are easily found in markets and residential gardens (Maciel et al., 2002).

Hyptidendron canum (Pohl ex Benth.) Harley (syn: Hyptis cana Pohl ex Benth) is a Savannah plant from the Lamiaceae

\footnotetext{
* Corresponding Author: Tatiana de Sousa Fiuza, Instituto de Ciências Biológicas, Departamento de Morfologia - ICB IIIUniversidade Federal de Goiás C.P. 131 - 74001-970, Goiânia - GO, Brazil. Tel: +55 62 3521-1485; Fax: +55 62 35211109, E-mail adress: tatianaanatomia@gmail.com Tel: +55 62 99882324; Fax: +55 62 3521-1109
} 
family. Members of this family consist of herbs, bushes and occasionally trees, normally odoriferous and usually presenting quadrangular branches. $H$. canum is found mainly in the central plateau of Brazil, in the states of Goiás, Mato Grosso and part of Minas Gerais (Fernandes and Lee, 1998). Its roots and leaves are used to make tea (infused or decocted) (Brandão, 1991) with antimalarial, anti-inflammatory, anti-ulcerative and anti-hepatotoxic effects (Ferri and Ferreira, 1992).

There are no detailed studies in the literature regarding the possible therapeutic activity and cellular toxicity of the crude ethanol extract and fractions of $H$. canum. To have data on cytotoxicology of the extract of this plant, teleostean fish Nile tilapia (Oreochromis niloticus L.) were used as an experimental model.

Fish have been used in scientific research as experimental models for environmental toxicology, genetics, cancer research, experimental biology and aquaculture in view of cost-effective advantages offered by their use in comparison to using mammals, birds, reptiles and amphibians (Bolis et al., 2001). Toxicological studies, using the tilapia as a model, are valid due to a number of characteristics, such as rapid growth, adaptability to varied diets, high resistance to illnesses, handling practices, easy reproduction in captivity and adequate endurance in a wide variety of environmental conditions (FontaínhasFernandes, 1998). All these factors determined the choice of this species for the testing of $H$. canum extract. Fish liver was used for this study as it plays an important part in many vital functions of the basic metabolism and is also the largest organ responsible for accumulation, biotransformation and contaminant excretion, including pesticide degradation and bio- activation (Matos et al., 2007).

The objective of this study was (1) to test the bioactivity of the crude ethanol extract and the ethyl acetate, hexanic and chloroform fractions, obtained from the leaves of $H$. canum, on the hepatopancreas of Oreochromis niloticus Linnaeus, (2) to verify the effects on cells and tissues (3) to establish the Nile tilapia as an experimental model for the study of extracts and fractions from plants of the Brazilian Savannah.

\section{MATERIAL AND METHODS}

\section{Material}

Leaves of Hyptidendron canun (Pohl ex Benth.) Harley, were collected from the municipality of Goiânia, Goiás $\left(16^{\circ} 43^{\prime}\right.$ 26.1" $\mathrm{S}$ and $49^{\circ} 15^{\prime} 54.8^{\prime \prime} \mathrm{W}$, at an altitude of $885 \mathrm{~m}$ ), from February through April 2005. The species was identified by Prof. Dr. José Realino de Paula from the Federal University of Goiás (UFG). A voucher specimen was deposited in the herbarium of that institution under registration number $\mathrm{UFG} / 29862$. The leaves were oven dried with air circulation at $40^{\circ} \mathrm{C}$ and then ground in a knife mill.

Preparation of the ethanol extract, fractions and their chromatographic profile by thin layer chromatography (TLC)

The $H$. canum leaf powder was extracted three times by maceration with ethanol $(96 \%)$ at a 1: 3 proportion at room temperature over a period of twenty-four hours. The extract was then filtered and concentrated in a rotaevaporator at a temperature of $\leq 40^{\circ} \mathrm{C}$.

To obtain the fractions, the ethanol extract was dissolved in methanol, to which distilled water was added until a $\mathrm{MeOH} /$ $\mathrm{H} 2 \mathrm{O}$ (7: 3) solution was obtained. The resulting solution was extracted by means of successive liquid-liquid partitioning with hexane, chloroform and ethyl acetate. The hexanic, chloroformic and ethyl acetate fractions obtained were concentrated in a rotaevaporator at a temperature of $\leq 40^{\circ} \mathrm{C}$ (Ferri, 1996).

The TLC analyses were performed with the following solvent mixtures for mobile phases: acetone, toluene / phormic acid (3: 3: 1). The fractions were re-dissolved in absolute ethanol and applied to TLC plate 
containing silicagel 60 F254 (Merck). For the detection of the main characteristic compounds, the following were used: $\mathrm{FeCl}_{3} / \mathrm{HCl}$, vanilline- $\mathrm{H}_{2} \mathrm{SO}_{4}, \mathrm{KOH}$ at $10 \%$, NP $1 \%$ (diphenilboric acid $1 \%$ in methanol) / PEG (poliethyleneglycol) 4000 at 5\% in ethanol, anisaldehide sulphuric acid. The compounds on TLC plates were detected by visible light at UV $(365 \mathrm{~nm})$, and analyzed according to Wagner and Bladt (2001).

\section{Experimental model}

The male Nile tilapias were obtained from the Fishculture sector in the School of Veterinary Medicine in the Federal University of Goiás. The fish were weighed and kept in $100 \mathrm{~L}$ tanks supplied with wellaired water at the proportion of $100 \mathrm{~L}$ per hour (Raceway system) and fed a commercial extruded feed 4 to $6 \mathrm{~mm}$ in diameter containing $32 \%$ protein twice daily at 9 a.m. and 4 p.m. Each fish was kept in a box with two smaller specimens for one week before the experiment, in order to adapt them to the new environment. The experiment was performed from March through June 2007.

Every week pH, temperature and ammonia and oxygen content in the water were measured with an Alfakit Card Kit (Brazil).

Throughout the experiment total ammonia content in the water remained constant at $0.5 \mathrm{mgL}-1, \mathrm{O}_{2}$ content varied from 5.9 to $6.5 \mathrm{mg} \mathrm{O} \mathrm{O}_{2} \mathrm{~L}-1$ and water temperature varied from $19.5^{\circ} \mathrm{C}$ to $26^{\circ} \mathrm{C}$.

The feed containing extracts and fractions was prepared one day before the experiment. Extracts and fractions were calculated according to animal weight, diluted in $96 \%$ ethanol and mixed with previously weighed feed. After total ethanol evaporation at room temperature, the feed was weighed once again. The number of pellets containing the crude extract and fractions was calculated according to the daily pellet consumption by the fish during the adaptation week. On the day of the experiment an average of 2 to 3 pellets were administered containing the $H$. canum material in an adequate dosage for each fish. The pellets with ethanol extract or fractions were ingested by the animals. Tilapias weighing an average of $229 \pm 57.8$ $\mathrm{g}$ and 19.8 to $26.5 \mathrm{~cm}$ in length initially received a dose of $280 \mathrm{mgkg}-1$ of $H$. canum crude ethanol extract in their feed. After noting the effects on the hepatic tissue, the fish ingested the hexanic, chloroform and ethyl acetate fractions in a single dose in their feed after fasting for 18 hours. For the experimental analysis, the fish were grouped in pairs, to which the three concentrations of each fraction were administered as follows: $70 \mathrm{mgkg}-1,140$ mgkg- 1 and $280 \mathrm{mgkg}-1$. The control group received feed without the extract.

The fish were sacrificed 24 hours later by hypothermia followed by rapid decapitation as recommended by the Ministry of Agriculture in Brazil (Brasil, 1995). The livers were dissected, fixed in neutral formalin and dehydrated, then embedded in paraffin, and sectioned ( $3 \mu \mathrm{m}$ thickness). Masson's trichrome and HE staining were performed for histological analysis. The following staining procedures were performed for histochemical evaluation: Feulgen (for DNA detection), PAS and PAS+ salivary amylase (to detect glycol conjugates) and Sudan IV (for lipid identification), where the fragments of fresh fish liver were frozen and sectioned at $10 \mu$ $\mathrm{m}$ thickness and stained. Subsequently the sections were dehydrated and the coverslips mounted in Entelan (Merck -USA). The qualitative analysis was performed with a light microscope and images recorded by an Olympus CH-30 photomicroscope.

The experiments described were performed in accordance with the ethical principles for animal research determined by the Brazilian Collegiate for Animal Experimentation (COBEA).

\section{RESULTS}

Preparation of the ethanol extract, fractions and chromatographic profile in $T L C$

The crude ethanol extract yield from the $H$. canum leaf powder was $8.66 \%$. The crude extract fraction yield was $29.61 \%$ for the 
hexane fraction, $23.79 \%$ for the chloroform fraction, and $4.13 \%$ for the ethyl acetate fraction.

The TLC analysis indicated the presence of terpenes in the hexane fraction, terpenes and flavonoids in the chloroform fraction, while the ethyl acetate fraction contained flavonoids and lignans.

\section{Macroscopic analyses}

None of the fish perished throughout the experiment. The tilapia livers treated with the crude ethanol extract and fractions presented normal anatomical appearance in a dark red color. Only the fish treated with the chloroform fraction presented visible blood vessel dilation and blood congestion. No necroses, vesiculose formations, vessel rupturing or hemorrhages were observed.

\section{Light microscopy}

\section{Hepatopancreas-control group}

The liver sections from the animals in the control group presented normal appearance, containing polyhedral hepatocytes with a central or sub central nucleus, arranged in two cell rows bordered by sinusoids. The sinusoids emerged from a central vein in a radial distribution, often star shaped. Groups of hepatocytes with central capillaries were noted in transverse section, giving the hepatic tissue a general roseate appearance. Some rodlet cells (RCs) were noted around the veins. Pancreatic-venous tract $(\mathrm{P}-\mathrm{VT})$, pancreatic venous-biliary tract (P- VBT) and pancreatic venous arteriolar tract (P-VAT) were noted among the hepatocytes characterizing the liver as a hepatopancreas (Fig. 1). The pancreocytes could be seen as islets with their own lamellar lining in an acinar pattern surrounding a branch of the portal vein, with the nucleus in the basal portion of the cell. In the materials stained with Masson's trichrome, orangey zimogen granules were noted in the apical region of the pancreocytes. Under HE staining pole of the pancreocytes was basophilic and the cytoplasm of the apical region was eosinophilic. Near the pancreocytes a few eosinophilic granular cells (EGCs), rodlet cells (RCs) and occasionally adipocytes and polimorphonucleares (PMs) could be seen. The veins presented endothelial cells and a few erythrocytes. Most of the biliary ducts were joined to the pancreocytes by an outer layer of smooth muscle fibers, a middle layer rich in collagen, a simple ciliated cylindrical epithelium (larger ducts) and a simple cubical epithelium (smaller ducts) limiting light.

The pancreocyte cytoplasm was generally PAS positive and amylase resistant, therefore containing neutral glycoproteins and occasionally glycogen. The Sudan IV reaction showed the presence of lipid droplets inside the hepatocytes. Normal hepatocytes presented a vacuolized appearance due to cytoplasmic inclusions (glycogen and lipid droplets).

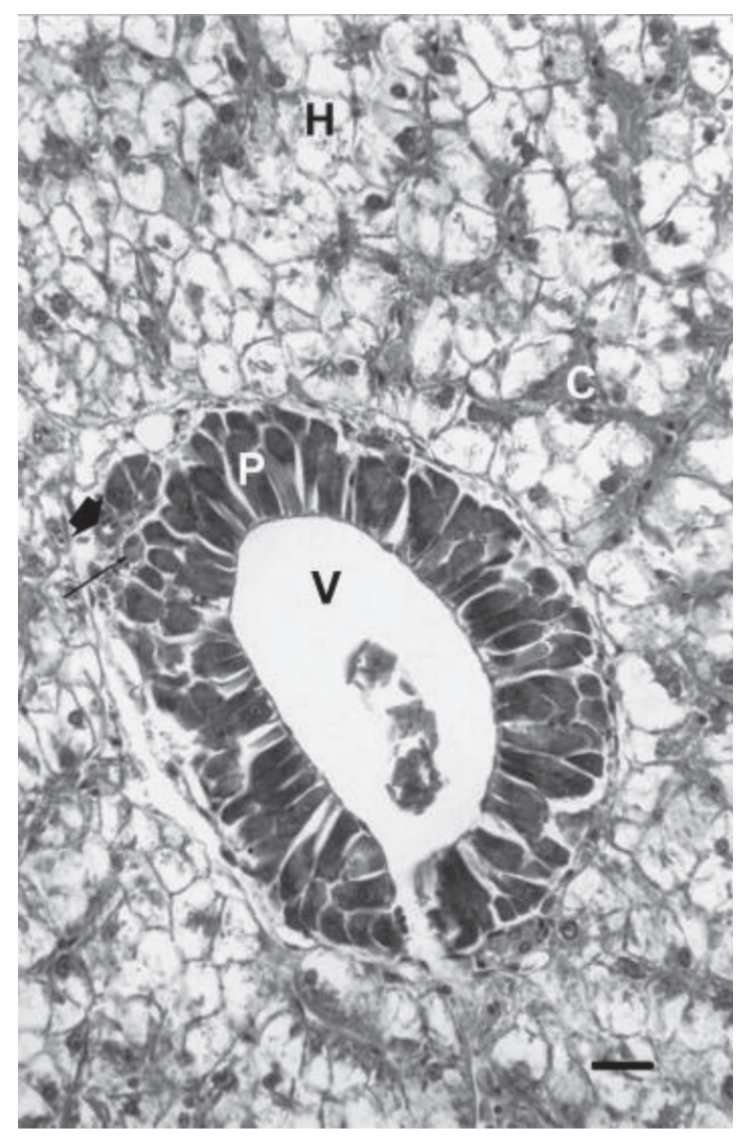

Figure 1: Control Group. P-VAT. RC (rodlet cell) (smaller arrow) and arteriole (larger arrow) noted. $\mathbf{C}=$ capillary; $\mathbf{H}=$ hepatocyte; $\mathbf{P}=$ pancreocyte; $\mathbf{V}=$ vein. $\mathrm{HE} .40 \mathrm{X}$. Bar $=50 \mu \mathrm{m}$. 
The Feulgen analysis did not diagnose the presence of micronuclei either in the control group or in the treated groups.

\section{Hepatopancreas after treatment with crude ethanol extract}

The tilapia liver treated with $280 \mathrm{mgkg}$-1 of $H$. canum crude ethanol extract, presented slight capillary dilation, hepatocytes with the following characteristics: irregular walls, rupturing, apparent volume reduction, rounding, some presenting a greenish pigment in their interior and others apparently vacuolized. The presence of eosinophilic pancreocytes was noted either without granules or presenting lighter granules on the apical surface enveloping a blood congested vein. A number of eosinophilic granular cells (EGCs) were verified associated with the central vein (Fig. 2). P- VBAT with the presence of eosinophilic granular cells (EGCs) near the duct and rodlet cells (RCs) among the pancreocytes were also seen.

\section{Analysis of Hepatopancreas after treatment with chloroform fraction}

The tilapia hepatopancreas, which received the chloroform fraction in the 70, 140 and $280 \mathrm{mgkg}-1$ concentrations, presented altered pancreocytes with apparent volume reduction, some with elongated appearance, with few or no apical granules. In this case the adipocytes occurred near the pancreocytes, occasionally accumulating (Fig. 3). A centroacinar cell was noted on the pancreatic acines.

Altered eosinophilic hepatocytes with irregular and sometimes ruptured walls were noted in all the concentrations. In the 140 and $280 \mathrm{mgkg}-1$ concentrations, the hepatocytes presented an apparent volume reduction, some rounded in shape and others with greenish pigmentation inside. The capillaries presented slight dilation in the 70 mgkg-1 concentration and larger dilations and congestion at higher concentrations.

A large number of rodlet cells (RCs) and eosinophilic granular cells (EGCs) associated to the pancreocytes were noted in the histological sections of the fish that received the three concentrations of this fraction. Some degranulating eosinophilic granular cells (EGCs) near the pancreocytes and the biliary ducts and rodlet cells (RCs) associated to the hepatocytes were noted in the $140 \mathrm{mgkg}-1$ concentration. A number of eosinophilic granular cells (EGCs) associated with the central vein, as well as leukocytic infiltrate and melanomacrophages (MMs) associated with the pancreocytes were noted in the $280 \mathrm{mgkg}-1$ concentration.

In the fish treated with the $70 \mathrm{mgkg}-1 \mathrm{a}$ hemorrhagic spot and rare giant foreign body cells associated to the pancreocytes were diagnosed. Lymphocytes were diagnosed within the vessels surrounded by

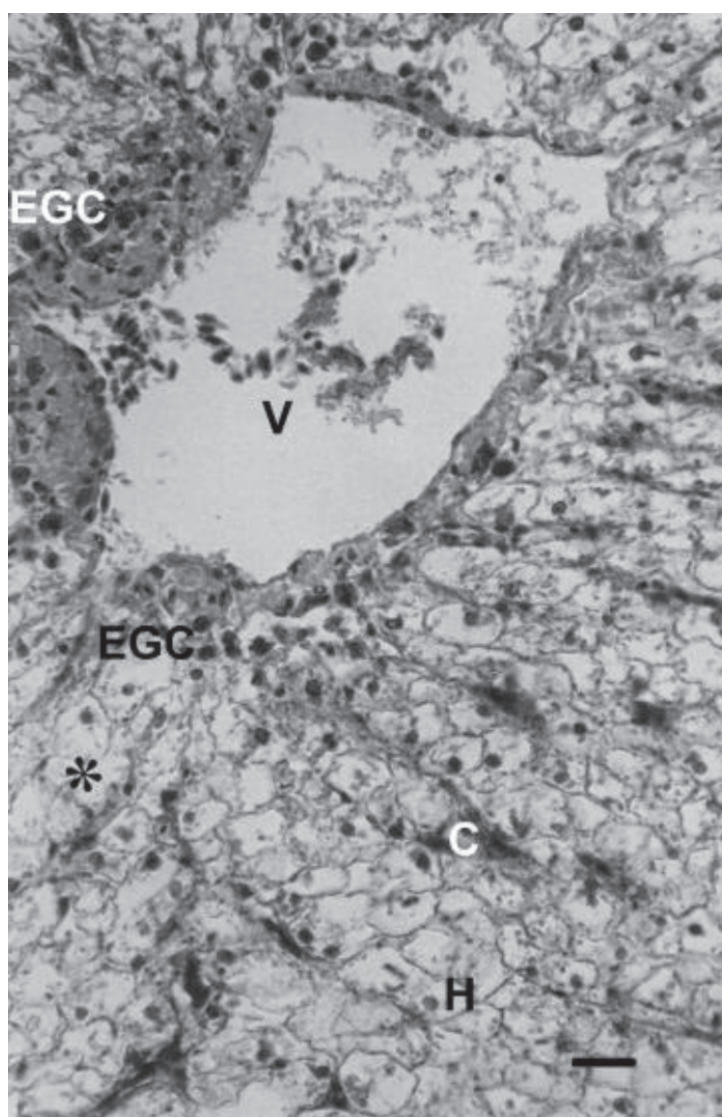

Figure 2: Histological section of tilapia hepatopancreas that received $280 \mathrm{mgkg}^{-1}$ of crude ethanol extract. Several EGCs (eosinophilic granular cells) associated to the central vein, ruptured hepatocytes (asterisk). C = capillary; $\mathbf{H}=$ hepatocyte $; \mathbf{V}=$ vein. Masson's trichrome. $40 \mathrm{X}$. Bar $=50 \mu \mathrm{m}$. 
the pancreocytes in those treated with 140 mgkg-1. A vein with several greenish pigments in its interior was noted in the fish that received $280 \mathrm{mgkg}-1$ of this fraction.

\section{Effect of ethyl acetate fraction on Hepatopancreas}

The analyses of the histological sections of tilapia livers that received 70, 140 and 280 mgkg-1 of the ethyl acetate fraction revealed eosinophilic hepatocytes with apparent volume reduction, others rounded, vacuolized and voluminous, some with greenish pigments inside. A rosette-shaped structure with hepatocytes spread around a dilated capillary was detected. The hepatocytes of the fish that received the 280

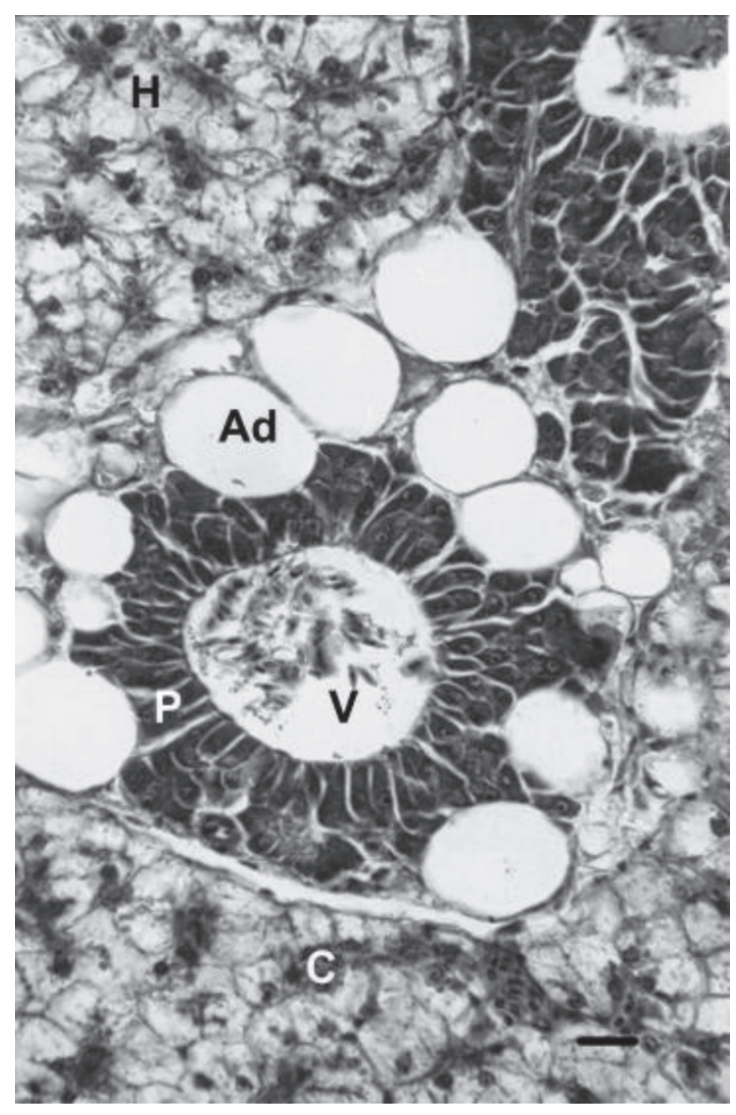

Figure 3: Histological section of fish that ingested pellets with $70 \mathrm{mgkg}^{-1}$ of chloroform fraction. Altered pancreocytes with associated adipocytes. $\mathbf{A d}=$ adipocyte $\mathbf{C}=$ capillary; $\mathbf{H}=$ hepatocyte; $\mathbf{P}=$ pancreocyte; $\mathbf{V}=$ vein. $\mathrm{HE}$. 40X. Bar $=50 \mu \mathrm{m}$. mgkg-1 of this fraction also presented ruptured irregular walls and in some regions an apparent reduction in the number of hepatocyte nuclei were noted, while other regions presented leukocytic infiltrate. Blood congested dilated vessels were noted in all three concentrations and the tilapias that received $70 \mathrm{mgkg}-1$ of this fraction also presented an apparent increase in the number of capillaries widespread over the hepatic tissue.

At all three concentrations employed there were RCs and EGCs associated with the pancreocytes. However, leukocytic infiltrate was observed in the fish that received 70 and $140 \mathrm{mgkg}-1$, associated adipocytes were seen at a dose of $70 \mathrm{mgkg}$ 1 and a few melanomacrophages (MMs) in those treated with 140 mgkg-1 (Fig. 4). The tilapia liver sections that received $70 \mathrm{mgkg}$ 1 of this fraction also presented EGCs associated with the biliary ducts and the central vein, as well as focal necroses. In the fish that received 140 and $280 \mathrm{mgkg}-1$ of the ethyl acetate fraction, the pancreocytes had very light granules in the apical region.

\section{Effects of hexanic fraction on Hepatopancreas}

The hepatic tissue of the fish that received 70 mgkg-1 of the hexanic fraction presented normal hepatocytes. The hepatocytes in those that received $140 \mathrm{mgkg}-1$ presented irregular walls, smaller sizes and shape alterations. In both concentrations, some hepatocytes presented greenish pigments inside. The tilapias that received $280 \mathrm{mgkg}$ 1 of the hexanic fraction presented intensely eosinophilic hepatocytes, some rounded in shape and irregular or ruptured walls.

The blood vessels of the fish treated with 70 mgkg-1 presented slight dilation and vascular congestion, whereas those treated with 140 and $280 \mathrm{mgkg}-1$ were dilated, congested and presented an apparent increase in the number of capillaries rich in eosinophilic cells. Blood vessels with irregular walls were noted in the fish that received the highest concentration. The presence of focal 
necroses was detected in the hepatic parenchyma and biliary ducts with irregular walls (Fig. 5) in the groups treated with 140 and $280 \mathrm{mgkg}-1$ of the hexanic fraction. A number of EGCs and leukocytic infiltrate were identified near the biliary ducts in the animals treated with $280 \mathrm{mgkg}-1$ of the fraction.

A few RCs associated with the central vein were seen in fish treated with the 70 mgkg-1 concentration, and a large number of EGCs and the presence of giant foreign body cells were observed in those exposed to the $140 \mathrm{mgkg}-1$ concentration, as well as various EGCs and some RCs in the blade region characteristic of the central veins in the fish that received $280 \mathrm{mgkg}-1$.

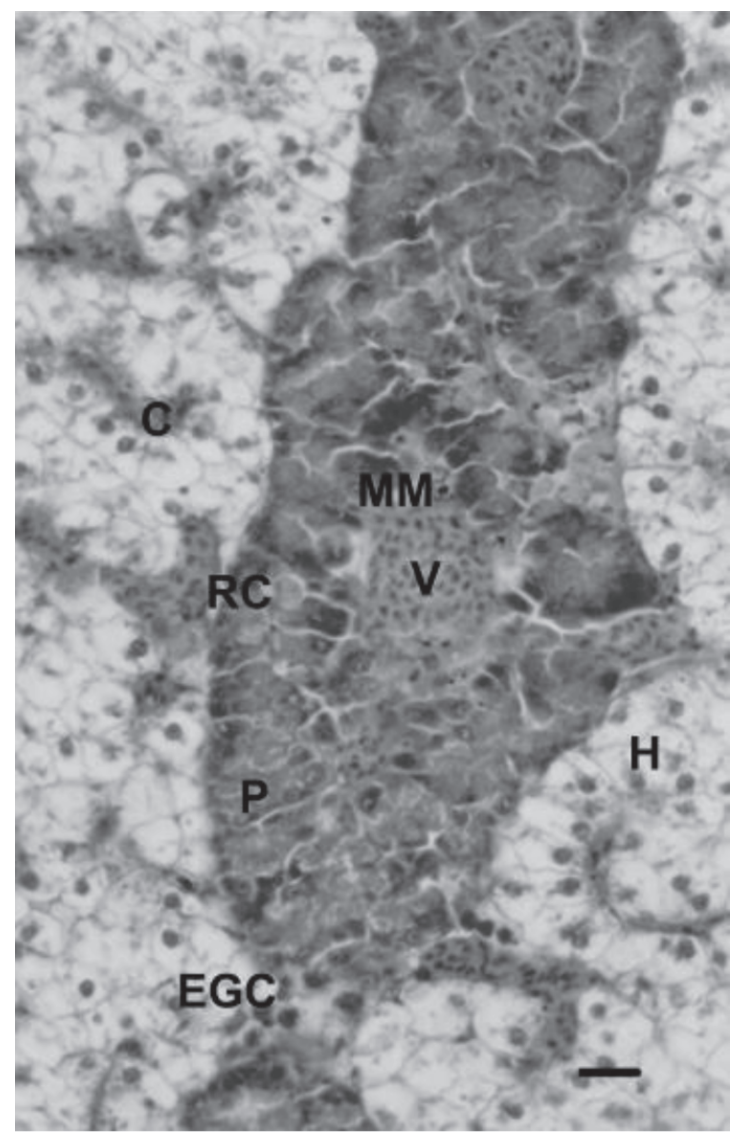

Figure 4: Hepatopancreas of fish that received pellets with $140 \mathrm{mgkg}^{-1}$ of ethyl acetate fraction. MMs and RCs associated to the pancreocytes. C = capillary; $\mathbf{E G C}=$ eosinophilic granular cells; $\mathbf{H}=$ hepatocyte; $\mathbf{M M}=$ aggregated melanomacrophage; $\mathbf{P}=$ pancreocyte; $\mathbf{R C}=$ rodlet cell; $\mathbf{V}=$ vein. HE. $40 \mathrm{X}$. Bar $=50 \mu \mathrm{m}$.
A few RCs, some EGCs and adipocytes associated with the exocrine pancreas were observed in the lower concentration, and leukocytic infiltrate, EGCs and adipocytes fish treated with the 140 mgkg-1 concentration (Fig. 6). The pancreocytes presented an elongated appearance, thin walls and lighter apical region surrounding a blood-congested vein with associated EGCs in the tilapias that ingested 140 and $280 \mathrm{mgkg}-1$ of the hexanic fraction.

The presence of a hemorrhagic spot was detected in the hepatic parenchyma with a large amount of erythrocytes, EGCs and a number of dilated capillaries with greenish content in the fish treated with $70 \mathrm{mgkg}-1$, and the presence of leukocytic cells was seen in those treated with $280 \mathrm{mgkg}-1$.

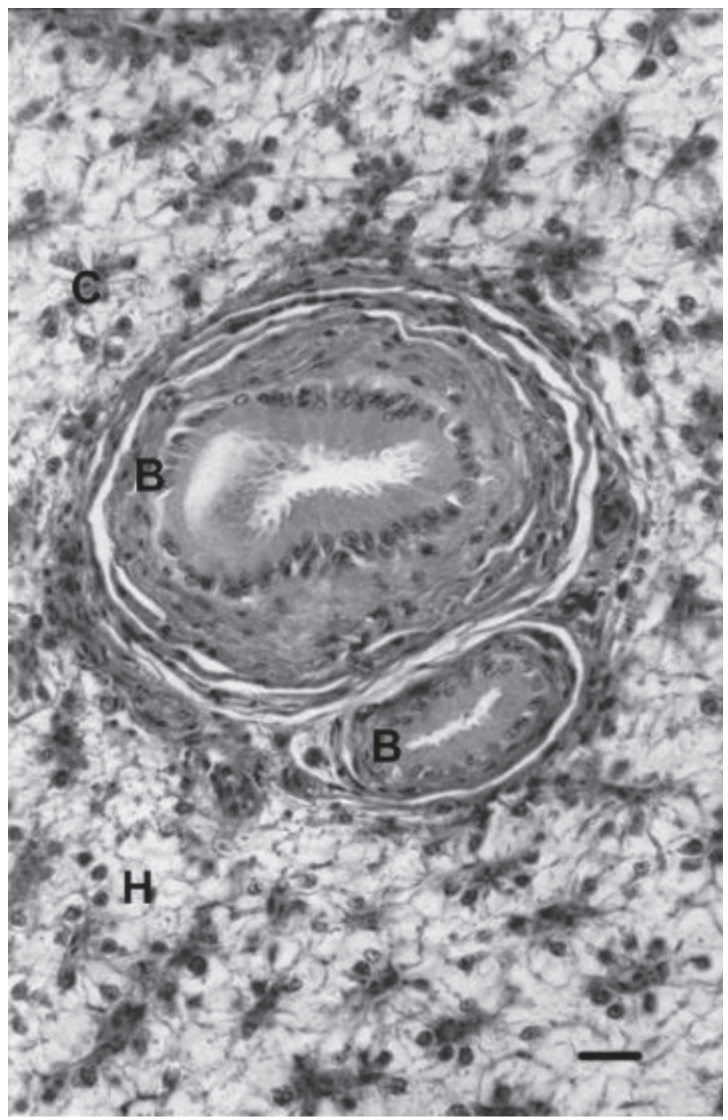

Figure 5: Hepatic section of tilapias that received pellets with $140 \mathrm{mgkg}^{-1}$ of the hexanic fraction. Biliary ducts with irregular walls. $\mathbf{B}=$ biliary duct; $\mathbf{C}=$ capillary; $\mathbf{H}=$ hepatocyte. HE. 40X. Bar $=50 \mu \mathrm{m}$. 


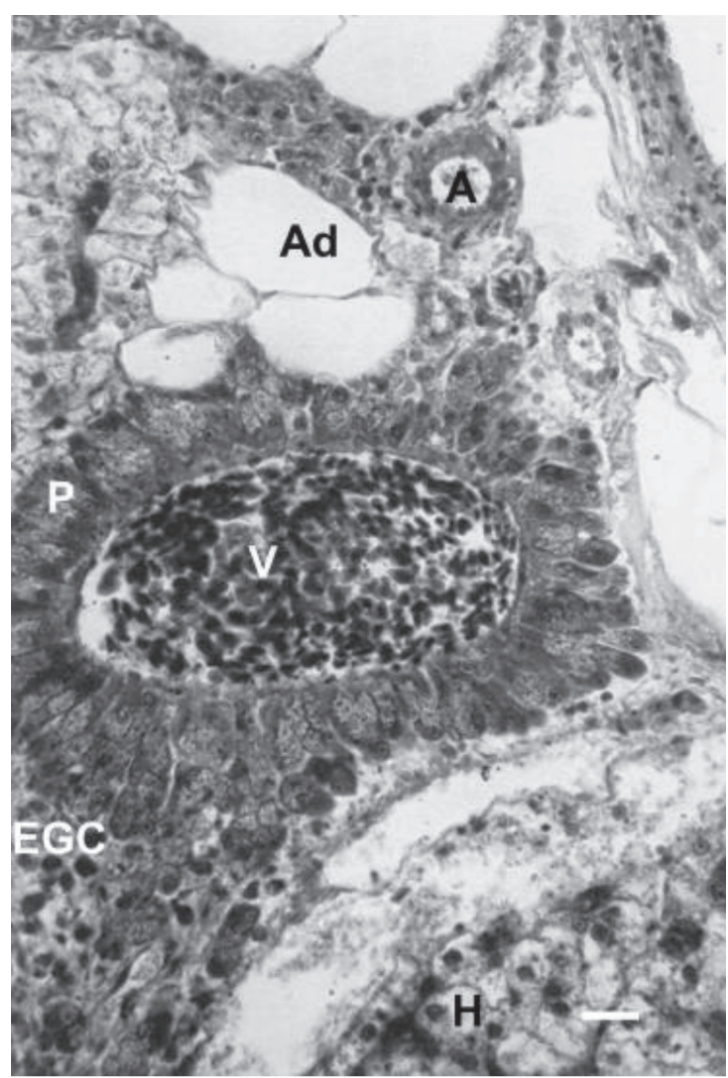

Figure 6: Hepatic section of tilapias that received pellets with $140 \mathrm{mgkg}^{-1}$ of the hexanic fraction. Adipocytes and EGCs associated to pancreocytes. A= arteriole; $\mathbf{A d}=$ adipocyte; EGC = eosinophilic granular cells; $\mathbf{H}=$ hepatocyte; $\mathbf{P}=$ pancreocyte; $\mathbf{V}=$ vein . Masson's trichrome. 40X. Bar $=50 \mu \mathrm{m}$.

\section{DISCUSSION}

This study detected an increase in the alterations in the hepatopancreas of Nile tilapias, concomitantly with the increase in concentrations of the crude extract and fractions, in comparison with the control group pattern.

Normal Nile tilapia hepatocytes are more vacuolized than mammalian hepatocytes. This is due to the relatively larger amount of lipid and/or glycogen reported by Ferguson (1989). This fact was confirmed in this study with the presence of glycogen and lipids detected in the hepatocyte cytoplasm.

Other than hepatocytes, a few PMs, EGCs and MMs were noted in the normal tilapia liver. The EGCs, known as mastocytes in mammals, are regularly found in fish liver and they are probably inflammatory cells, part of the defense system (Jordanova et al., 2007). The MMs are pigmented cells and their increase is related to advanced stages of chronic inflammation and responses to severe tissue lesions, as well as cellular responses to a number of infections (Agius and Roberts, 1981). This study did not diagnose any increase in the number of EGCs, MMs, PMs or RCs in the control group. In other words, the liver in the control group presented normal appearance, without any significant alterations or inflammatory processes.

The liver sections from the fish that received the three concentrations of the chloroform fraction presented a large number of RCs and EGCs and leukocytic infiltrate at the highest concentration. Leino (1996) suggested that the RCs may be stimulated by certain substances produced as a result of tissue injury or related factors, and is reminiscent of leukocyte responses and various chemothatic stimuli. The increase in RCs and EGCs in the present study suggests a possible irritant and/or toxic activity by the chloroform fraction, which probably led to the inflammatory response in the tilapia liver.

The following alterations were noted in the exocrine pancreas in the hepatopancreas sections from the tilapias that received the crude ethanol extract and chloroform fraction: vacuolization, a decrease in cytoplasmic volume and in the number of zimogen granules. These alterations were also noted in zebrafish (Henry et al., 1997) that were exposed to 2,3,7,8 tetrachlorodibenzo- $\rho$-dioxin. According to Dezfuli et al. (2000) the pancreas suffers the greatest pathological alterations in its cells, probably due to its function (high content of hydrolytic enzymes). This suggests that the chloroform fraction contains some irritant substance (probably terpenes and flavonoids) since it induces alterations in the tilapia hepatopancreas.

The blood vessels presented dilation and blood congestion in all the experimental groups, especially in the fish that received 
the higher concentrations. Tilapias that ingested the 140 and 280 mgkg-1 concentration of the hexanic fraction, presented an apparent increase in the number of capillaries with eosinophilic content, probably indicating the proliferative action of this fraction due to the presence of terpenes in its chemical constitution.

The following were observed in the histological sections of the tilapias that received the crude ethanol extract and the three fractions: hepatocytes with irregular walls, apparently shrunken, with altered shapes, others rounded vacuolized and enlarged (ethyl acetate fraction). According to Ferguson (1989) these alterations may be due to a loss of glycogen and/or lipids in the hepatocytes, common morphological responses in the liver of fish exposed to toxic agents.

Microscopically, hepatocellular vacuolization diminishes and the hepatocytes may become larger or smaller than expected, depending on the etiology. Paradoxically, exposure to toxic agents may also result in the accumulation of fat or glycogen in the liver (Wolf and Wolf, 2005), which leads to the increase in hepatocyte volume, as noted in the hepatic sections of the fish that received the ethyl acetate fraction. It is suggested that this reaction is due to flavonoids in this fraction. These observations suggest that the crude ethanol extract and the fractions of $H$. canum are toxic to tilapia hepatocytes as they cause similar cellular and tissue reactions to those described in the literature regarding fish exposed to several harmful agents.

Focal necroses in the hepatic parenchyma were seen in the fish that received the hexanic and ethyl acetate fractions. Similar necroses were also found in tilapias exposed to streptozotocine (Wright et al., 1999) and copper (Figueiredo-Fernandes et al., 2007). The presence of focal necroses in the tilapia livers in the present study suggests a toxic nature in the chemical components of these fractions.

The animals treated with the crude extract presented most of the alterations noted in the fractions, but with less intensity. The crude extract contained a lower concentration of all the chemical constituents found in the fractions, which may explain the less severe affect.

This study concludes that the crude ethanol extract in the $280 \mathrm{mgkg}-1$ concentration and the 70,140 and 280 mgkg-1 concentrations of the fractions from $H$. canum leaves present vasoactive activity, causing vasodilation and vascular congestion of greater or lesser degrees and some toxicity due to the presence of EGCs, $\mathrm{RCs}$, leukocytic infiltrate and rare focal necrosis. The hexanic fraction also caused the apparent proliferation of blood capillaries. The H. canum may be used as an antihypertensive drug in the future, yet further studies using smaller doses of the crude ethanol extract and fractions are necessary to attempt reduction of the toxic effects of this plant and evaluate the presence of the vasodilator effect.

The Nile tilapia proved to be a satisfactory model to screen plant products. This is the first description of the biologic action of the crude ethanol extract and fractions of $H$. canum in fish.

\section{ACKNOWLEDGEMENTS}

The authors thank the Foundation to Support for Research, the Faculty of Pharmacy/UFG, the Institute of Biological Sciences/UFG, the Department of Animal Production, the School of Veterinary Medicine/UFG and would also like to thank Sharon Lois Vinaud for the translation into English.

\section{REFERENCES}

AGIUS C, ROBERTS RJ (1981) Effects of starvation on the melanomacrophage centers of fish. J Fish Biol 19: 161-169

BOLIS CL, PICCOLELLA M, DALLE VALLE AZ, RANKIN JC (2001) Fish as model in pharmacological and biological research. Pharmacol Res 44: 265-280

BRANDÃO M (1991) Plantas Medicinais do Ce rrado Mineiro. Inf Agropec 15: 15-20

BRASIL (1995) Ministério da Agricultura, do Abastecimento e da Reforma Agrária. Sistema de Análise de Riscos e Pontos Críticos naIndústria da Pesca: manual de procedimentos. Versão preliminar. Rio de Janeiro: SENAI/DN/DET 
DEZFULI BS, SIMONI E, ROSSI R, MANERA M (2000) Rodlet cells and other inflammatory cells of Phoxinus phoxinus infected with Raphidascaris acus (Nematoda). Dis Aquat Org 43: 61-69

FERNANDES COS, LEE CC (1998) Detecção da atividade genotóxica (cromoteste e induteste) da planta medicinal do Cerrado: Hyptidendron canum (mata-pasto) em cepas bacterianas. Resumo dos anais do VI Seminário de Iniciação Científica na UFG. pp: 57-58

FERRI S, FERREIRA HD (1992) Fitoquímica das folhas deHyptis Benth. Semana de Química. pp: 1-32

FIGUEIREDO-FERNANDES A, FERREIRA-CARDOSO JV, GARCIA-SANTOS S, MONTEIRO SM, CARROLA J, MATOS P, FONTAÍNHASFERNANDES A (2007) Histopathological changes in liver and gill epithelium of Nile tilapia, Oreochromis niloticus, exposed to waterborne copper. Pesq Vet Bras 27: 103-109

FONTAÍNHAS-FERNANDES AA (1998) Tilápia production. In: REIS-HENRIQUES MA (ed) Aquaculture Handbook. pp: 135-150

GINGERICH WH (1982) Hepatic toxicology of fishes. In: WEBER LJ (ed.) Aquatic Toxicology. pp: 55-105

GUARIN NETO G, MORAIS RG (2003) Recursos Medicinais de espécies do Cerrado de Mato Grosso: um estudo bibliográfico. Acta Bot Bras 17: 561-584

HENRY TR, SPITSBERGEN JM, HORNUNG MW, ABNET CC, PETERSON RE (1997). Early life stage toxicity of $2,3,7,8$-tetrachlorodibenzo- $\square_{j}$-dioxin in zebrafish (Danio rerio). Toxicol Appl Pharmacol 142: 56-58

JORDANOVA M, MITEVA N, ROCHA E (2007) A quantitative study of the hepatic eosinophilic granule cells and rodlet cells during the breeding cycle of
Ohrid trout, Salmo letnica Kar (Teleostei, Salmonidae). Fish Shellfish Immunol 23: 473-478

LEINO RL (1996) Reaction of rodlet cells to a myxosporean infection in kidney of the bluegill, Lepomis macrochirus. Can J Zool 74: 217-225

MACIEL MAM, PINTO AC, VEIGA JR (2002) Plantas medicinais: a necessidade de estudos multidisciplinares. Quim Nova 25: 429-438

MATOS P, FONTAÍNHAS-FERNANDES A, PEIXOTO F, CARROLA J, ROCHA E (2007) Biochemical and histological hepatic changes of Nile tilápia Oreochromis niloticus exposed to carbaryl. Pestic Biochem Physiol 89: 73-80

MITERMEIER N, MYERS RA, MITTERMEIER CG (1999) Hotspots- Earth's Biologically Richest and Most Endangered Terrestrial Ecoregions. Mexico City: CEMEX-Conservation International. $430 \mathrm{pp}$

RATTER JA, RIBEIRO JF, BRIDGEWATER S (1997) The Brazilian Cerrado vegetation and threats to its biodiversity. Ann Bot 80: 223-230

SILVA LO, COSTA DA, FILHO KES, FERREIRA HD, BRANDÃO D (2002) Levantamento florístico e fitossociológico em duas áreas de Cerrado sensu stricto no Parque Estadual da Serra de Caldas Novas, Goiás. Acta Bot Bras 16: 43-53

WAGNER H, BLADT S (2001) Plant Drug Analysis. A Thin Layer Chromatography Atlas. 2rd ed. New York/ Tokio: Springer-Verlag Berlin Heidelberg. 384 pp

WOLF JC, WOLF MJ (2005) A brief overview of nonneoplastic hepatic toxicity in fish. Toxicol Pathol 33: $75-85$

WRIGHT JJ, ABRAHAM C, DICKSON BC, YANG H, MORRISON CM (1999) Streptozotocin dose-response curve in tilapia, a glucose-responsive teleost fish. Gen Comp Endocrinol 114: 431-440. 